Language Education and Language Acquisition

\title{
Information on Visual Impairment across Countries
}

\author{
Cunhat Hiago \\ Research Institute for Special and Inclusive Education \\ *Corresponding author's email: cunhathiago@gmail.com
}

\section{DEFINITION}

There are four categories of visual impairments: i.e. normal vision, moderate visual impairment, severe visual impairment and blindness. In moderate or severe visual impairment, we speak of low vision. When the person is totally or almost blinded, we speak of blindness. The term visual impairment includes both low vision and blindness. The term low vision is a more common term for low vision.

\section{TYPES OF VISUAL IMPAIRMENT}

We can note three main types of visual impairment which, depending on the degree of intensity, range from low vision to blindness:

- Blurred vision: difficult perception of contrasts and reliefs, poor evaluation of distances, attenuated colors.

- Peripheral vision with central scotoma: manifests itself by the appearance of a spot in the center of the retina, where the person visually fixes his attention. People with this type of 
visual impairment manage to move around in space without difficulty, but their perception of details and colors is greatly impaired.

- Tubular vision: the person sees as if through a keyhole. Visual acuity may be normal, but the person has great difficulty moving around, especially in the dark.

The most frequent phenomena, isolated or which may accompany visual impairment: disorders of the fixation reflex (nystagmus); perception of a duplicate image (diplopia); brightnessrelated disorders (photophobia); low night vision; color vision abnormalities. Visual information gathering and difficulties encountered. Most of the problems encountered by pupils with visual impairment are linked to difficulties in taking visual information on the one hand and transmitting the knowledge acquired in writing on the other; Difficulties in learning to read and having access to texts, graphics and images affect learning, in all disciplines.

Several auxiliary means and aids make it possible to overcome these difficulties (e.g. visual aids for reading "in black" or enlargement software) or can replace our usual writing system (e.g. Braille writing, audio media or automatic audio and braille transcription systems). To understand the difficulties that students encounter in their learning and in the classroom, it is important to learn about their specific visual handicap, their own difficulties and their impact on their learning, as well as the strategies they have implemented to deal with it.

\section{DIFFERENTIATED PEDAGOGY}

Each student with a visual impairment will have different needs, so only those selected from the accommodations described below are adapted to the individual situation of the student: 
- Acceptance and social integration: develop mutual aid and collaboration between students; explain the specific difficulties of the student concerned, their particular needs and the reasons for the arrangements made.

- Organization and consistency of the class space: allocate fixed places to all students; ensuring order in the classroom; do not move objects without informing the affected student.

- Student movements: in class, avoid obstacles, do not leave objects lying around on the ground and add markers; when traveling in a new environment, appoint an accompanying companion.

- Positioning of the pupil: to find the most adequate place, take into account the specific handicap of the pupil and take care of the lighting, the noise as well as its location in relation to the blackboard and his comrades.

- Verbalization and taking reference points: use precise terms of places to designate a location; to speak to the maximum; describe what is going on; allow the student to put marks (tactile or visual) to better find themselves in a text.

- Written information: provide written information in the most suitable form, taking into account the student's particular handicap. Prepare structured, clean documents, free of unnecessary information; ensure the cleanliness of the supports, the contrasts between the writing and the supports, the legibility of the characters and the accessibility of the information displayed in the classroom.

- Solicit senses other than sight in learning: let the student touch objects; accomplish with him the gestures that an activity requires; attract his attention by special non-visual signs; allow her to respond orally rather than in writing. 
- Attitude to adopt: provide the necessary help while respecting the student's autonomy; concerning the rules of life in the classroom, place the student on an equal footing with his peers.

- Pay particular attention to the student's posture; signs of fatigue; that he understands the words he uses; inform in certain situations so that he can adapt his attitude adequately.

People with disabilities are legally entitled to compensation for disadvantages, provided that the principle of proportionality is respected, that is to say that the ratio between the resources invested in eliminating inequality and the benefits obtained is balanced. Very generally, compensation for disadvantages can be defined as neutralizing or reducing the limitations caused by a disability. It means the arrangement of the conditions under which learning and exams take place and not an adaptation of the education / training objectives. The list of measures to compensate for disadvantages for visually impaired students proposed below is not exhaustive. These must in any case be allocated according to the particular situation, the age and the educational level of the pupil.

\section{REFERENCES}

Agesa, L. (2014). Challenges faced by learners with visual impairments in inclusive setting in Trans-Nzoia County. Journal of Education and Practice, 5(29), 185-192.

Arslantaş, T. K. (2017). Foreign language education of visually impaired individuals: A review of pervasive studies. IHEAD: Ihlara Journal of Educational Research, 2(2), 95-104. 
Birchler, K., \& Michaelow, K. (2016). Making aid work for education in developing countries: An analysis of aid effectiveness for primary education coverage and quality. International Journal of Educational Development, 48, 37-52.

Bolt, D. (2005). From blindness to visual impairment: Terminological typology and the social model of disability. Disability \& Society, 20, 539-552.

Casper, M. J., \& Talley, H. L. (2005). Preface: Ethnography and disability studies. Journal of Contemporary Ethnography, 34(2), 115-120.

Danforth, D., \& Gabel, S. L. (2006). Vital questions facing disability studies in education. New York, NY: Peter Lang.

Davis, L. J. (2002). Bending over backwards: Disability, dismodernism, and other difficult positions. New York, NY: New York University Press.

DePoy, E., \& Gilson, S. F. (2011). Studying disability: Multiple theories and responses. Thousand Oaks, CA: Sage.

Eckes, A., Großmann, N., \& Wilde, M. (2018). Studies on the effects of structure in the context of autonomy-supportive or controlling teacher behavior on students' intrinsic motivation. Learning and Individual Differences, 62, 69-78.

Florian, L. (2008). Special or inclusive education: Future trends. British Journal of Special Education, 35(4), 202-208.

Gabel, S. L. (2005). Disability studies in education: Readings in theory and method. New York, NY: Peter Lang.

Hersh, M. A., \& Johnson, M. A. (2008). Disability and assistive technology systems. In M. A. Hersh \& M. A. Johnson (Eds.), Assistive technology for visually impaired and blind people (pp. 1-50). London: Springer. 
Jenks, E. B. (2005). Parents' stories of raising children with visual impairments in a sighted world. Journal of Contemporary Ethnography, 34, 143-169.

Masino, S., \& Zarazúa, M. N. (2016). What works to improve the quality of student learning in developing countries? International Journal of Educational Development, 48, 53-65.

Melie, S., William, G., Susanto, S., \& Nanda, D. S. (2020). Foreign language training for visually impaired students in South East Asian countries. https://doi.org/10.31219/osf.io/vjrng

Nanda, D. S. (2016, May). Fostering the Use of Drama for English Language Learners in the Efl Classroom. In International Conference on Education and Language (ICEL) (p. 7).

Nugent, M. (2018). Reframing inclusion: An exclusive-inclusive approach. British Journal of Special Education, 45(2), 141-156.

Siebers, T. (2006). Disability theory. Ann Arbor, MI: University of Michigan Press.

Susanto, S. (2016). A case study of prosodic phrasal grouping and intonational prominence in language acquisition. English Review: Journal of English Education, 4(2), 289-295.

Susanto, S., \& Nanda, D. S. (2018). Teaching and learning English for visually impaired students: an ethnographic case study. English Review: Journal of English Education, 7(1), 8392.

Thompson, R. G. (1997). Extraordinary bodies: Figuring physical disability in American culture and literature. New York, NY: Columbia University Press.

Whitburn, B. (2014). Accessibility and autonomy preconditions to 'our' inclusion: A grounded theory study of the experiences of secondary students with vision impairment. Journal of Research in Special Educational Needs, 14(1), 3-15.

Zhou, M. (2016). The roles of social anxiety, autonomy, and learning orientation in second language learning: A structural equation modeling analysis. System, 63, 89-100. 